\title{
Prevalence of Medical Comorbidities in Adults with Autism Spectrum Disorder
}

\author{
Natascia Brondino, MD, PhD ${ }^{7}$, Laura Fusar-Poli, MD, PhD², Emanuela Miceli, MD', \\ Michele Di Stefano, MD', Stefano Damiani, MD' ${ }^{7}$, Matteo Rocchetti, $\mathrm{MD}^{\top}$, and \\ Pierluigi Politi, $M D, P h D^{7}$
}

'Department of Brain and Behavioral Sciences, University of Pavia, Pavia, Italy; ${ }^{2}$ Department of Clinical and Experimental Medicine, Psychiatry Unit, University of Catania, Catania, Italy; ${ }^{3}$ Department of Internal Medicine, IRCCS San Matteo Hospital Foundation, University of Pavia, Pavia, Italy.

KEY WORDS: medical comorbidity; prevalence; autism spectrum disorder; physical examination.

J Gen Intern Med 34(10): 1992-4

DOI: $10.1007 / \mathrm{s} 11606-019-05071-\mathrm{x}$

(c) Society of General Internal Medicine 2019

\section{INTRODUCTION}

Autism spectrum disorder (ASD) is characterized by difficulties in socioemotional reciprocity and communication. ${ }^{1}$ Impairments in communication represent an important obstacle when clinicians are confronted with the challenge of diagnosing comorbidities in ASD. In fact, nonverbal or minimally verbal individuals with ASD could have difficulties in communicating symptoms, and problem behaviors, such as self-injury or aggression, could be sometimes the only manifestation of an underlying medical problem. Additionally, due to sensory impairment or refusal to initiate requested tasks, noncompliance to medical examination (i.e., palpation or auscultation) or different types of medical procedure (i.e., MRI, venipuncture) is extremely common. ${ }^{2}$ These difficulties may result in important unmet medical needs in this population. Only one study ${ }^{3}$ has actually investigated the presence of medical comorbidities in adult with ASD, while the others have relied on patient/caregiver survey or medical charts/registers. The aim of the present study is to evaluate medical comorbidities in a sample of adults with ASD.

\section{METHODS}

This is a cross-sectional observational study performed at the Autism Laboratory of the University of Pavia, Italy, between January 2013 and January 2018. Individuals were considered eligible if they had a diagnosis of ASD performed in the past or during the current assessment. Level of severity for each of the two main criteria of DSM 5 was attributed to each subject. Medical history was recorded, and each reported diagnosis (i.e., allergic reactions, metabolic disorders) was reinvestigated to obtain a clinical confirmation. Congenital diseases for which appropriate documentation and genetic testing were provided

Published online May 29, 2019 were not reinvestigated. Additionally, each patient underwent a complete neurological and physical evaluation. Each observed sign or symptom was subsequently investigated by specific instrumental testing or by referral to the appropriate medical specialist. Blood tests were prescribed if performed more than 6 months before evaluation. All comorbidities were classified according to the ICD-10 system.

\section{RESULTS}

During the study period, 191 subjects received a diagnosis of ASD and were included in the study (Table 1). Presence of at least one medical comorbidity was observed in 114 subjects $(59.7 \%)$. The number of comorbidities per subject varied from one to four (Table 2). Overall, epilepsy is the most represented medical condition $(n=29,15.18 \%)$, followed by allergic rhinitis $(n=17,8.9 \%)$ and irritable bowel syndrome $(n=13,6.8 \%)$.

Presence of medical conditions was not different between men and women $\left(\chi^{2}=0.17, p=0.68\right)$. Patients with ASD and

Table 1 General Characteristics of the Study Sample $(n=191)$

\begin{tabular}{ll}
\hline \hline Variables & Mean \pm SD or $\boldsymbol{n , ~ \%}$ \\
\hline Age (years) & $24.04 \pm 8.36$ \\
Gender, male & $144,75.4 \%$ \\
Cognitive impairment & $80,41.9 \%$ \\
ASD DSM 5 severity & \\
Level 1 & $43,22.5 \%$ \\
Level 2 & $76,39.8 \%$ \\
Level 3 & $72,37.7 \%$ \\
Familiar history of ASD & $5,2.6 \%$ \\
Familiar history of psychiatric disorders & $27,14.1 \%$ \\
Marital status & $182,95.3 \%$ \\
Single & $5,2.6 \%$ \\
Married & $4,2.1 \%$ \\
Separated/divorced & $111,58.1 \%$ \\
Employment status & $59,30.9 \%$ \\
Unemployed & $12,6.3 \%$ \\
Student & $9,4.7 \%$ \\
Employed & $108,56.5 \%$ \\
Sheltered job & $71,37.2 \%$ \\
Current use of psychotropic medication & $39,15.7 \%$ \\
Antipsychotic & $44,23 \%$ \\
Antidepressant & $29,15.2 \%$ \\
Antiepileptic/mood stabilizers & \\
Benzodiazepine & \\
\hline
\end{tabular}


Table 2 Type of Medical Comorbidities

\begin{tabular}{|c|c|}
\hline Type of condition & $n$ \\
\hline $\begin{array}{l}\text { Certain infectious and parasitic diseases } \\
\text { Chronic viral hepatitis C }\end{array}$ & $\begin{array}{l}1 \\
1\end{array}$ \\
\hline Neoplasms & 6 \\
\hline Myeloid leukemia, remitted status & 1 \\
\hline Stomach cancer & 1 \\
\hline Breast cancer, remitted status & 1 \\
\hline Meningioma & 1 \\
\hline Benign neoplasm of brain, supratentorial occipital & 1 \\
\hline Essential thrombocythemia & 1 \\
\hline \multicolumn{2}{|l|}{$\begin{array}{l}\text { Diseases of the blood and blood-forming organs and certain } \\
\text { disorders involving the immune mechanism }\end{array}$} \\
\hline Hereditary deficiency of factor $\mathrm{V}$ & 1 \\
\hline Iron deficiency anemia & 1 \\
\hline \multicolumn{2}{|l|}{ Endocrine, nutritional, and metabolic diseases } \\
\hline Nontoxic multinodular goiter & 1 \\
\hline Autoimmune thyroiditis & 1 \\
\hline Hypothyroidism, unspecified & 2 \\
\hline Type 2 diabetes mellitus & 1 \\
\hline Obesity & 11 \\
\hline Hyperhomocysteinemia & 2 \\
\hline Polycystic ovarian syndrome & 2 \\
\hline Diseases of the nervous system & 40 \\
\hline Epilepsy & 29 \\
\hline Migraine & 3 \\
\hline Other headache syndromes & 3 \\
\hline Disorder of trigeminal nerve, unspecified & 1 \\
\hline Late-onset cerebellar ataxia & 1 \\
\hline Cataplexy & 1 \\
\hline Spastic paraplegia & 2 \\
\hline Diseases of the eye and adnexa & 5 \\
\hline Keratoconus & 2 \\
\hline Blindness, binocular & 1 \\
\hline Hemianopsia & 1 \\
\hline Convergent concomitant strabismus & 1 \\
\hline Diseases of the ear and mastoid process & 3 \\
\hline Conductive hearing loss, bilateral & 1 \\
\hline Hearing loss, unspecified & 1 \\
\hline Benign paroxysmal vertigo & 1 \\
\hline Diseases of the circulatory system & 9 \\
\hline Essential (primary) hypertension & 1 \\
\hline Orthostatic hypotension & 1 \\
\hline Varicose veins of lower extremities & 2 \\
\hline Aortic aneurysm of the bulb, without rupture & 1 \\
\hline Mitral (valve) prolapse & 1 \\
\hline Long QT syndrome & 1 \\
\hline Supraventricular paroxysmal tachycardia & 1 \\
\hline Raynaud syndrome & 1 \\
\hline Diseases of the respiratory system & 19 \\
\hline Chronic asthmatic bronchitis & 2 \\
\hline Allergic rhinitis due to pollen & 13 \\
\hline Allergic rhinitis to animal & 4 \\
\hline Diseases of the digestive system & 38 \\
\hline Constipation & 12 \\
\hline Irritable bowel syndrome & 13 \\
\hline Gastroesophageal reflux disease & 3 \\
\hline Esophagitis & 1 \\
\hline Eosinophilic gastroenteritis & 1 \\
\hline Perianal abscess & 1 \\
\hline Microscopic colitis & 1 \\
\hline Achalasia of cardia & 1 \\
\hline Nonalcoholic fatty liver disease & 2 \\
\hline Solitary ulcer of anus & 1 \\
\hline Gluten sensitivity & 1 \\
\hline Allergic gastroenteritis & 1 \\
\hline Diseases of the skin and subcutaneous tissue & 10 \\
\hline Lichen sclerosus et atrophicus & 2 \\
\hline Alopecia universalis & 1 \\
\hline Psoriasis & 1 \\
\hline Atopic dermatitis & 3 \\
\hline Seborrhoeic dermatitis & 1 \\
\hline Hypertrichosis & 1 \\
\hline Pilonidal cyst & 1 \\
\hline Diseases of the musculoskeletal system and connective tissue & 10 \\
\hline Systemic lupus erythematosus & 1 \\
\hline
\end{tabular}

(continued on next page)
Table 2. (continued)

\begin{tabular}{ll}
\hline \hline Type of condition & $\boldsymbol{n}$ \\
\hline Scoliosis & 4 \\
Osteoporosis without pathological fracture & 1 \\
Flat foot & 1 \\
Lumbago due to displacement of intervertebral disc & 1 \\
Radial styloid tenosynovitis (de Quervain) & 1 \\
Scheuermann's disease (juvenile kyphosis) & 1 \\
Diseases of the genitourinary system & 6 \\
Chronic kidney disease & 1 \\
Calculus of kidney & 1 \\
Vesicoureteral reflux-associated uropathy & 1 \\
Recurrent and persistent hematuria & 1 \\
Hydrocele & 1 \\
Endometriosis & 1 \\
Congenital malformations, deformations, and chromosomal & 10 \\
abnormalities & 1 \\
Rieger anomaly & 1 \\
Arteriovenous malformation of cerebral vessels & 2 \\
Tuberous sclerosis & 1 \\
Ulerythema ophryogenes & 1 \\
Multiple congenital exostoses & 1 \\
Ehlers-Danlos syndrome & 1 \\
Accessory toe & 1 \\
Renal hypoplasia, unilateral & 1 \\
Klippel-Trénaunay-Weber syndrome & 3 \\
Symptoms, signs, and abnormal clinical and laboratory findings, & 3 \\
not elsewhere classified & \\
Sinusal tachycardia & 2 \\
Isolated hyperCKemia & 1 \\
\hline
\end{tabular}

ID displayed more frequently medical comorbidities $\left(71.3 \%\right.$ vs $\left.52.3 \%, \chi^{2}=6.93, p=0.01\right)$. Additionally, ASD individuals taking psychotropic medications were more likely to have medical conditions compared with ASD individuals not taking medications $(72.0 \%$ vs $43.8 \%$, $\left.\chi^{2}=15.17, p<0.001\right)$. There was a positive correlation between the number of medical comorbidities and age (rho $=0.17, p=0.02$ ) and DSM 5-rated severity of ASD $($ rho $=0.27, p<0.001)$.

\section{DISCUSSION}

Our study showed a complex picture of medical comorbidities in ASD. Prevalence rate of epilepsy was higher in our sample compared with that in general population $(15.18 \%$ vs $7.9 \%)$, but in line with data from the adult ASD population . ${ }^{4}$ Prevalence of allergic rhinitis was low compared with that in the Italian population ( 8.9 vs $15-25 \%$ ) and that in an autistic sample $(16 \%) .{ }^{5}$ As people with ASD were examined throughout different years and seasons, it is possible that we have underestimated the true prevalence of seasonal allergic rhinitis.

Our findings did not report significant sex differences in accord with a previous investigation. ${ }^{4}$ The same report ${ }^{4}$ showed a reduction in the rate of comorbidities with aging, in contrast with our results. However, Supekar mainly investigated medical conditions typical of childhood and did not consider metabolic disorders which may appear later in life. 
Subjects with ASD and comorbid ID presented a higher rate of medical comorbidities. This could be related to the higher health risk burden of people with ID in general. ${ }^{6}$

This is the first comorbidity study based on direct observation and examination of patients by experienced clinicians. Additionally, this is the first study to actually screen for a variety of medical comorbidities in adults with ASD, which represent an understudied population.

In conclusion, people with ASD presented a mixed pattern of medical comorbidities. Physicians caring for adults with ASD should be aware of the possible presence of comorbid conditions, which could go unnoticed given the communication impairment inherent to ASD.

Corresponding Author: Natascia Brondino, $M D, P h D$; Department of Brain and Behavioral Sciences University of Pavia, Pavia, Italy (e-mail: natascia.brondino@unipv.it).

\section{Compliance with Ethical Standards:}

Conflict of Interest: The authors declare that they do not have a conflict of interest.

\section{REFERENCES}

1. Lord C, Elsabbagh M, Baird G, Veenstra-Vanderweele J. Autism spectrum disorder. Lancet. 2018;392(10146):508-20. doi:https://doi. org/10.1016/S0140-6736(18)31129-2

2. Riviere V, Becquet M, Peltret E, Facon B, Darcheville JC. Increasing compliance with medical examination requests directed to children with autism: effects of a high-probability request procedure. J Appl Behav Anal. 2011;44(1): 193-7. doi:https://doi.org/10.1901/jaba.2011.44-193

3. de Winter CF, Bastiaanse LP, Hilgenkamp TI, Evenhuis HM, Echteld MA. Cardiovascular risk factors (diabetes, hypertension, hypercholesterolemia and metabolic syndrome) in older people with intellectual disability: results of the HA-ID study. Res Dev Disabil. 2012;33(6):1722-31. doi:https://doi.org/10.1016/j.ridd.2012.04.010

4. Supekar K, Iyer T, Menon V. The influence of sex and age on prevalence rates of comorbid conditions in autism. Autism Res. 2017;10(5):778-89. doi:https://doi.org/10.1002/aur.1741

5. Zerbo O, Leong A, Barcellos L, Bernal P, Fireman B, Croen LA. Immune mediated conditions in autism spectrum disorders. Brain Behav Immun. 2015;46:232-6. doi:https://doi.org/10.1016/j.bbi.2015.02.001

6. Havercamp SM, Scott HM. National health surveillance of adults with disabilities, adults with intellectual and developmental disabilities, and adults with no disabilities. Disabil Health J. 2015;8(2):165-72. doi:https://doi.org/10.1016/j.dhjo.2014.11.002

Publisher's Note Springer Nature remains neutral with regard to jurisdictional claims in published maps and institutional affiliations. 